\title{
ENGENHARIA BIOMÉDICA APLICADA À REABILITACAO EM PÓS-OPERATÓRIO DE MASTECTOMIA
}

\author{
João Vitor da Silva Moreira' \\ Mario Oliveira Lima ${ }^{2}$ \\ Fernanda Roberta Marciano ${ }^{3}$
}

\begin{abstract}
Resumo: O objetivo deste trabalho é desenvolver uma ferramenta para auxiliar no processo de recuperação pós-operatória de procedimentos de mastectomia. Utilizando de ferramentas de reconhecimento corporal e interfaces virtuais, serão quantificados os dados relacionados à amplitude de movimento de ambos os braços dos pacientes, agindo como uma ferramenta de acompanhamento de progresso para as terapias de Reabilitação desenvolvidas no Laboratório de Engenharia de Reabilitação Sensório-motora. Com isto, será possivel avaliar a evolução dos pacientes caso a caso, bem como determinar a eficácia/eficiência das alternativas de terapia que empregam Realidade Virtual (VR). Para a captura dos dados de posicionamento corporal utiliza-se a câmera Kinect ${ }^{\circledR}$ da Microsoft, presente no console Xbox 360. Esta dispõe de uma biblioteca de fonte aberta, a qual torna possivel explorar suas ferramentas como desenvolvedor, e utilizar o máximo potencial de seus algoritmos de reconhecimento corporal e facial. Ao final, espera-se tornar possivel quantificar o progresso obtido com as interfaces virtuais já presentes no laboratório, dando caráter ainda mais técnico às pesquisas ali desenvolvidas.
\end{abstract}

Palavras-chave: Realidade Virtual; Kinect; Reabilitação; Mastectomia; Câncer de Mama.

\footnotetext{
1 Instituto De Pesquisa \& Desenvolvimento/Universidade do Vale do Paraíba, Brasil. E-mail: joaovvitor@outlook.com.

2 Instituto De Pesquisa \& Desenvolvimento/Universidade do Vale do Paraíba, Brasil. E-mail: mol@univap.br.

3 Instituto De Pesquisa \& Desenvolvimento/Universidade do Vale do Paraíba, Brasil. E-mail: frmarciano@univap.br.
} 